\title{
Lengua y gramática en El Magisterio español (1871-1880)
}

\author{
María José García Folgado ${ }^{1}$ \\ Universitat de València-GIEL, España
}

\begin{abstract}
Resumen
Las cuestiones sobre la lengua y su enseñanza ocupan un lugar singular en la prensa del magisterio, dado que, por mandato legal, este era un aspecto central en la escuela y en la formación de maestros (Ezpeleta Aguilar, 2015: 159). Concretamente, en el caso de la gramática, las páginas periódicas acogen tanto artículos de índole teórica sobre la lengua, como trabajos didácticos con un enfoque eminentemente práctico, debates sobre aspectos gramaticales concretos, reseñas de obras gramaticales, etc. Todo ello hace de la prensa educativa un material de gran relevancia para conocer en profundidad el desarrollo de las ideas gramaticales.

En este trabajo, nos aproximamos a las ideas lingüísticas presentes en una de las publicaciones periódicas más longevas de la prensa especializada, el periódico El Magisterio Español (fundado en 1867), durante sus primeras décadas de existencia y, especialmente, en el periodo 1871-1880 dominado por la presencia como redactor de Fernando Gómez de Salazar.
\end{abstract}

Palabras clave: prensa pedagógica, gramática, enseñanza de la lengua, siglo XIX.

\footnotetext{
1 Para correspondencia, dirigirse a: M José García Folgado (maría.jose.garcia-folgado@) uv.es), Facultat de Magisteri, Avda. Tarongers, 4. 46022, Valencia. ORCID 0000-0002-51247471.
} 


\title{
LANGUAGE AND GRAMMAR IN EL MAGISTERIO ESPAÑOL
}

(1871-1880)

\begin{abstract}
Questions about language and its teaching occupy a special place in the pedagogical press, since this was a central aspect in school and in teacher training by legal mandate (Ezpeleta Aguilar, 2015: 159). Specifically, in the case of grammar, the periodical pages host both theoretical articles on the language, as well as didactic works with an eminently practical approach, debates on specific grammatical aspects, reviews of grammatical works, etc. All this makes the educational press a material of great relevance to know in depth the development of grammatical ideas.

In this paper, we approach the linguistic ideas present in one of the lasting periodical publications of the specialized press, the newspaper El Magisterio Español (founded in 1867), during its first decades of existence and, especially, in the period 1871-1880 dominated by the presence of Fernando Gómez de Salazar.
\end{abstract}

Keywords: pedagogical press, grammar, language teaching, 19th century.

Recibido: 14/01/21

Aceptado: 25/02/21

\section{INTRODUCCIÓN ${ }^{2}$}

El periódico El Magisterio español está considerado la publicación más longeva de la prensa pedagógica española (Esteban y López Martín 1992; Checa Godoy 1993-94). Fundado en 1867, surge como órgano que persigue "la defensa de los intereses y derechos de los catedráticos y maestros" (Gaceta de Madrid, n. ${ }^{\circ}$ 58, 7-VI-1867, p. 4) y se sitúa desde sus inicios como un referente para los docentes españoles, no solo por su rigurosidad y su talante liberal moderado, sino por su clara dedicación, casi con exclusividad,

2 Este trabajo se ha realizado en el marco del proyecto LinPePrensa, Ideas lingüisticas y pedagógicas en la prensa española del siglo XIX (ref. PGC2018-098509-B-I00), concedido en la convocatoria de 2018 de proyectos de I+D de "Generación de conocimiento" (Ministerio de Ciencia, Innovación y Universidades). 
a los problemas profesionales, algo que se manifiesta ya desde sus primeras páginas (cf. Checa Godoy 1993-94. Véase también Sastre 1966, Eguibar 1992 y Vericat 1992) $)^{3}$.

Eguibar (1992) da cuenta de los detalles que condujeron a su fundación, a partir de reuniones de diversos catedráticos y profesores en el Ateneo de Madrid, encabezados por Mariano Carreras y González a los cuales

les preocupa que la información que genera la Dirección General de Instrucción Pública, dependiente del Ministerio de Fomento, no llegue a los profesores en el momento oportuno, sino con un retraso que les impide conocer de inmediato las leyes, decretos y directrices generales que repercuten en su propio trabajo como profesores y a su vez no les permiten defender a tiempo sus derechos y ejercitarse en sus deberes (1992: 107).

Efectivamente, una parte importante del espacio del periódico en sus primeras décadas está destinada a proporcionar a los docentes informaciones de orden legal y a dar a conocer los decretos y órdenes ministeriales y reglamentos (a veces con críticas, comentarios o explicaciones) en la denominada Sección oficial, así como a dar cuenta de cuestiones de orden práctico vinculadas a la profesión como las vacantes en las escuelas, el cierre y apertura de centros escolares, los resultados de oposiciones, nombramientos, etc. Asimismo, uno de sus objetivos principales es la defensa de los derechos del profesorado, con largos artículos publicados en la Sección orgánica, entre los que destacan los destinados a la libertad de cátedra y a la cuestión salarial (i.e., la columna "Martirologio", donde se expone la lista de "víctimas" de las malas condiciones que sufrían los maestros por no cobrar). Del mismo modo, en su propósito de atender a todos los aspectos de la vida profesional, se publican notas breves sobre la actividad en los distintos niveles de enseñanza, sobre premios y galardones, se informa de defunciones, se atiende a consultas diversas de los docentes, etc.

En este sentido, el diario también concede una gran importancia a los saberes profesionales, desde las cuestiones pedagógicas a los aspectos

\footnotetext{
Además de los diferentes prospectos publicados y las manifestaciones recurrentes al respecto en su Sección orgánica (que equivaldría a las actuales páginas editoriales), la propia denominación del periódico muestra claramente sus objetivos desde su subtítulo: "Órgano de todos los establecimientos de instruccion pública y privada -Universidades, Escuelas especiales, Institutos, Colegios, Escuelas Normales y de Primera Letras, etc.- consagrado especialmente á defender los intereses y derechos de catedráticos y maestros" (El Magisterio español, año I, n. ${ }^{\circ}$ 1, 8-V-1865). A partir de aquí, citamos el diario como EME.
} 
disciplinares, que se recogen principalmente en la Sección doctrinal y de los que es reflejo, asimismo, la Sección bibliográfica. En el caso de la primera, los contenidos que, según el propio diario, acoge son los siguientes:

Organizacion y reformas de la Instruccion pública en España y en el extranjero. -Métodos de enseñanza. -Programas. -Trabajos de las Academias y corporaciones sábias. - Lecciones ó conferencias profesadas en los establecimientos libres de enseñanza. -Estudios científicos y literarios" (EME, año II, Prospecto, 7-XII-1868).

En las páginas del periódico van a aparecer tanto artículos de índole teórica sobre cuestiones lingüísticas, como debates sobre aspectos gramaticales y ortográficos concretos, disquisiciones léxicas, reflexiones didácticas y notas diversas de orden lingüístico, entre otras cuestiones. Asimismo, en la sección bibliográfica, al hilo de la crítica de obras lingüísticas, se manifiestan ideas y posicionamientos teóricos sobre la lengua. A este respecto, cabe resaltar la diversidad de tipologías textuales (artículos, anuncios, reseñas, cartas, notas, etc.) a la que nos enfrentamos (vid. Puche 2019 y Gaviño en prensa; en prensa b), así como el hecho de que la lengua puede aparecer en las páginas del periódico de manera directa, en columnas que abordan algún tema lingüístico o de enseñanza de la lengua, o indirecta, en el caso de que las referencias a la lengua o su enseñanza aparezcan de manera tangencial o bien de que se trate de textos que, como indica Puche (2019: 183), abordan "cualquier tema, alejado siempre del ámbito lingüístico, aunque en su redacción se introduzca alguna explicación o glosa sobre determinadas palabras, expresiones, construcciones, usos ortográficos o expresión oral o escrita de un individuo, principalmente".

Por último, muchos de los temas que se plantean se alargan en diferentes números del periódico, en lo que Durán (2018) denomina "ciclos polémicos" y conforman un entramado complejo no solo por la diversidad tipológica a la que ya se ha aludido (una reseña, en la sección bibliográfica, puede motivar la publicación de una carta de réplica del autor reseñado, de uno o varios artículos en la sección doctrinal, de notas breves en la sección orgánica, etc.), sino también porque en muchas ocasiones se conforma una red dialéctica entre diversas cabeceras (véase, por ejemplo, Gaviño en prensa), lo que dificulta en buena medida su rastreo.

Hasta 1870, el diario se caracteriza desde el plano de los aspectos lingüísticos y pedagógicos por poner el foco en la enseñanza de las lenguas clásicas y una orientación más hacia la segunda enseñanza y la enseñanza superior que hacia la primera educación en las secciones doctrinal y bibliográfica; así, de los nueve artículos (varios de ellos publicados en partes) que se localizan en el periodo 1867-1869 sobre aspectos lingüísticos 
o lingüístico-pedagógicos, cuatro de ellos se destinan a las lenguas clásicas ${ }^{4}$ : "Programa de perfección del latín y principios generales de literatura", de Ozcáriz y Lasaga (EME, año I, n. ${ }^{\circ} 4,30-\mathrm{V}-1867$ y n. $\left.{ }^{\circ} 6,15-\mathrm{VI}-1867\right) ;$ "El uso del latín en Alemania" (EME, año I, n. ${ }^{\circ}$ 23, 23-X-1867); "Organización de los estudios clásicos" ( $E M E$, año I, n. $\left.{ }^{\circ} 25,20-X I-1867\right)$ y "Cuatro palabras sobre el estudio del latín" de Ramírez y Laguardia (EME, año III, n. ${ }^{\circ} 12,10$ II-1869, n. ${ }^{\circ} 14,20-$ II-1869 y n. $\left.{ }^{\circ} 16,28-I I-1869\right)$, uno a la cátedra de lengua sánscrita en la Universidad Central firmado por Balbín Unquera (EME, año III, n. ${ }^{\circ}$ 59, 5-IX-1869) y, por último, uno sobre el griego moderno "El porvenir de la lengua griega", de Rouvray (EME, año I, n. ${ }^{\circ} 11,3-\mathrm{VII}-1867$ y n. ${ }^{\circ} 13,8$-VIII-1867). Asimismo, en 1868 se publica una serie de artículos titulados "Carácter y extensión de la segunda enseñanza según J. Stuart Mill", cuya $3^{\mathrm{a}}$ parte (EME, Año II, n. ${ }^{\circ} 3$, 4-II-1868) se ocupa de las enseñanzas lingüísticas en ese nivel educativo y, en especial, se insiste en las ventajas del estudio de las lenguas clásicas frente a otras: "ninguna lengua de la moderna Europa ofrece la enseñanza que las de Grecia y Roma, con un mecanismo a la vez regular y complicado". Algo similar ocurre en la Sección bibliográfica, con una presencia mucho mayor de textos y manuales destinados al latín y al francés, ambas materias de segunda enseñanza, o traducciones de obras literarias latinas y griegas.

Relacionado con esta orientación hacia la segunda enseñanza, un aspecto interesante de este periodo inicial es que se manifiesta en los artículos y reseñas una clara tendencia hacia los presupuestos de la gramática de raigambre filosófica que relaciona expresión lingüística y expresión del pensamiento como dos caras de una misma moneda. Precisamente, en este periodo, y significativamente en la etapa Secundaria, los modelos lógicofilosóficos son la referencia fundamental para la enseñanza en un marco en el que, siguiendo los postulados entre otros de Destutt de Tracy, la enseñanza filosófica se configura como base para las ciencias, especialmente las morales y políticas, así como fundamentación teórica para las enseñanzas

4 Tres de ellos se destinan a la educación de los sordomudos (EME, año II, n. ${ }^{\circ}$ XI, 4-VI1868), al dictado (EME, año II n. ${ }^{\circ} 12,20$-VI-1868) y, desde una perspectiva más crítica que didáctica al aprendizaje de la lectura y la escritura (Fermín Caballero, EME, año III, n. ${ }^{\circ} 13$, 15-II-1869 y n. ${ }^{\circ} 15,25-$-II-1869). No hemos considerado en esta lista artículos que abordan cuestiones que, si bien a primera vista pueden relacionarse con el tema que nos ocupa, no lo abordan desde una perspectiva lingüística o didáctica (v. gr. "El arte de la declamación", de Pizarroso, EME, año I, n. ${ }^{\circ} \mathrm{X}, 15-\mathrm{VII}-1867$ y n. $^{\circ} 12$, 30-VII-1867 o "Caracteres fisiognómicos de la escritura", EME, año III, n. ${ }^{\circ} 53,5$-IX-1869). 
lingüísticas (vid. García Folgado 2019) artículo sobre Stuart Mill, en el que se habla de la gramática como "la parte más elemental de la lógica, en razon á que sus principios y reglas se proponen hacer que correspondan las formas de lenguaje á los modos universales del pensamiento" (EME, año II, n. ${ }^{\circ} 3$, 4-II-1868), como en la crítica que Miranda y Egía hace al Curso de Literatura general. La poesía y la palabra de F. de Paula Canalejas (EME, año II, n. ${ }^{\circ} 20$, 20-I-1868), donde Miranda explicita la relación entre la gramática y la psicología: "Siendo la psicología el fundamento de la gramática, la oracion de esta se formará á semejanza de la proposicion de aquella". Asimismo, se evidencia un cierto interés por el comparativismo, vinculado con la enseñanza superior (algo que también aparece con posterioridad), en las "Conferencias de arqueología sagrada" de Pulido y Espinosa (EME, año I, n. $\left.{ }^{\circ} 19,8-\mathrm{X}-1867\right)$, así como en el ya mencionado artículo de Balbín sobre la cátedra de sánscrito en la Universidad Central.

En general, podemos considerar que esta clara preferencia por temas y cuestiones que afectan especialmente a los niveles medio y superior de la enseñanza es debida al hecho de que el director del periódico en los años 1867-68, Carreras y González, era catedrático en el Instituto de San Isidro de Madrid y entre 1868 y 1869, los redactores que firman habitualmente la sección doctrinal, como Ramírez y Laguardia ${ }^{6}$ y algunos de los colaboradores,

\footnotetext{
5 Esta importancia dada a la filosofía se manifiesta también en la utilización de ese término como halago; así, se alaba la Ortografía de la lengua española de Antonio Gómez y Ruiz en los siguientes términos: "Distínguese en efecto la obra del Sr. Gomez por su espíritu filosófico, por su método y por la claridad con que están expuestas las ideas, de manera que se hagan accesibles á todas las inteligencias" (EME, año I, n. ${ }^{\circ} 7,23-\mathrm{VI}-1867$, el subrayado es nuestro) y, por el contrario, en la reseña al Curso completo de latinidad de Quirós de los Ríos se critica a la gramática de la Academia por rutinaria y "anti-filosófica" (EME, año III, n. $\left.{ }^{\circ} 30,10-\mathrm{V}-1869\right)$.

6 Ramírez y Laguardia, quien fue profesor, entre otros centros, en el Instituto de $2^{\mathrm{a}}$ enseñanza de Logroño y en la Universidad Central, firma también en la Sección oficial en esos años artículos que se enmarcan completamente en la formación secundaria y superior, como un artículo sobre Quintiliano (EME, año III, n. ${ }^{\circ} 13,15-$ II-1869), otra serie sobre el sistema filosófico platónico (EME, año III, n. ${ }^{\circ} 21,25-$ III-1869; n. $^{\circ} 22,30-I I I-1869 ;$ n. $^{\circ} 23$, 5-IV-1869; n. ${ }^{\circ} 25,15-I V-1869$ y n. $\left.^{\circ} 27,25-I V-1869\right)$ y varias series sobre cuestiones literarias como la significación de Lope de Vega en la historia del arte dramático español (EME, año III, n. ${ }^{\circ} 17,5$-III-1869; n. ${ }^{\circ} 18,10-$ III-1869; n. ${ }^{\circ} 19,15-$-III-1869 y n. ${ }^{\circ} 20,20$-III, 1869) o sobre las "Causas fundamentales que determinan la existencia del teatro español" (EME, año III, n. ${ }^{\circ} 31,15-V-1869 ;$ n. $^{\circ} 37,15-V I-1869 ;$ n. $^{\circ} 41,5-V I I-1869 ;$ n. $^{\circ} 48,10-V I I I-1869$ y n. ${ }^{\circ} 52,30-$ VIII-1869). Ramírez y Laguardia seguirá interviniendo como redactor en los años siguientes, principalmente con columnas, tanto en la sección doctrinal como en la sección orgánica, destinadas a cuestiones generales sobre la enseñanza. No obstante, también vamos a encontrar
} 


\section{como Camús ${ }^{7}$, se vinculan también profesionalmente con instituciones de enseñanza secundaria y superior.}

En la década de 1870, el diario cambia claramente su foco, que se desplaza de las lenguas clásicas a los asuntos lingüísticos y gramaticales atingentes a la lengua castellana. Este cambio viene de la mano del que será uno de los redactores principales de El Magisterio Español entre $1871^{8}$ y 1879 (año de su fallecimiento), Fernando Gómez de Salazar, gramático ${ }^{9}$ y periodista ${ }^{10}$. Su interés por la gramática castellana queda ampliamente recogido en las

algunos artículos destinados a temas lingüísticos vinculados con la enseñanza media y superior y reseñas de obras diversas sobre la lengua latina, entre otras.

7 Alfredo A. Camús fue profesor de Literatura clásica griega y latina en la Universidad Central, y entre los meses de junio y noviembre de 1869 publica amplias reseñas comentadas de la traducción de Los Argonautas por León Bendicho y de la traducción de las obras completas de P. Virgilio Maron por Eugenio de Ochoa. Hemos considerado su papel en EME como colaborador, pese a que no aparece en el listado que se ofrece en el encabezamiento del periódico, atendiendo al criterio de Durán (2018: 425), quien considera que "conviene diferenciar entre los que participan con frecuencia en una cabecera, con cierta regularidad en la línea de sus aportaciones, a los que podemos propiamente denominar colaboradores, y quienes envían textos de manera episódica o irregular y [...] mantienen una relación más distante y accidental".

8 Nos consta que Gómez de Salazar se incorporó al diario en 1870, ya que la primera entrega de su artículo "Cuatro palabras sobre filología" es de diciembre, pero no ha sido posible consultar los números correspondientes a ese año.

9 Sus obras lingüísticas conocidas son Gramática de la lengua castellana (1869, con una $2^{\mathrm{a}}$ edición en vida del autor de 1874 y una $3^{\mathrm{a}}$, póstuma, de 1884), Compendio de la gramática de la lengua española (1870), Juicio crítico del Diccionario y de la Gramática últimamente publicados por la Academia Española exponiendo los muchos y gravísimos errores que ambas obras contienen (1871), Conjugación completa de todos los verbos irregulares castellanos, $y$ de los defectivos en los tiempos y personas que están en uso (1873, con una $2^{\mathrm{a}}$ ed. en 1878 y una edición póstuma, anotada por Julio Calcaño en 1890) y La ortografía al alcance de todos (1878), texto que obtuvo un gran éxito, con seis ediciones en dos años y que fue muy reeditado hasta las primeras décadas del siglo XX, como consta en BICRES V. Para ampliar sus datos biobibliográficos y el análisis de su figura como polemista, véase Gaviño (2021; en prensa).

10 Además de redactor en El Magisterio Español, tuvo una marcada presencia también en otras cabeceras de la época, tanto con la publicación de artículos originales, como por la reproducción de los artículos que publicó en el diario que nos ocupa (práctica muy habitual en la época); especialmente importante, desde el punto de vista de sus ideas gramaticales, son sus columnas en Los Lunes de El Imparcial, donde critica la gramática de la Academia. Se inicia la serie con dos artículos, publicados el 13 y el 20 de agosto de 1877, encabezados con dos preguntas: “¿Se enseña el castellano?” y “Sirve la gramática de la Academia para enseñarlo?" y continúa con una serie de artículos titulados "La gramática oficial vista por dentro", publicados entre el 15 de octubre y el 24 de noviembre de 1877. Estos artículos se recogen posteriormente como anejo en la $2^{\mathrm{a}}$ edición de su Conjugación completa de todos los verbos irregulares castellanos (1878). 
páginas del periódico ${ }^{11}$, tanto en artículos destinados a cuestiones teóricas, como en las columnas en las que polemiza sobre asuntos gramaticales diversos, critica los usos lingüísticos de sus contemporáneos o reseña sin pelos en la lengua tratados gramaticales. En todo ello, la crítica a la Academia va a ser una constante, si bien ese espíritu antiacadémico ya se encuentra en el diario antes de su llegada, vinculado, con toda probabilidad, al propio espíritu de un periódico poco dado a admitir cualquier imposición externa al cuerpo docente. En relación con este enfrentamiento casi constante del autor con la docta Institución, señala Gaviño (en prensa):

[S]u diálogo constante con la Academia como institución que representa el poder regulador sobre la lengua es en sí mismo una necesidad por hacerse valer socialmente, pero es, al mismo tiempo, una meditada estrategia en la que Gómez de Salazar (podríamos decir David) se enfrenta a la gigante Academia (su Goliat) en una lucha desequilibrada y sin posibilidades de victoria que sirve para llamar la atención y ganarse el favor de sus lectores.

De hecho, esta estrategia de Gómez de Salazar es evidenciada por alguno de sus oponentes, como es el caso de Fernández Bremon, quien, al abordar desde La Ilustración española y americana (año XXII, n. ${ }^{\circ}$ 30, 15-VIII-1877, p. 90) las columnas de Gómez de Salazar publicadas en Los Lunes de El Imparcial, señala:

Los lectores del Magisterio Español [...] conocíamos hace tiempo á un escritor modesto, que ha hecho estudios profundos de la lengua castellana, el Sr. D. Fernando Gómez Salazar. El público le conoce desde el lunes último como gramático consumado, merced á la gran tirada de El Imparcial, y á un artículo en el cual niega que en España se enseñe el castellano, toda vez que los jóvenes aprenden el idioma por la gramática de la Academia, que no lo enseña, á juicio del articulista.

Y, un poco más adelante: "El artículo del Sr. Gómez Salazar es interesante, y prueba gran estudio y conocimiento del idioma, mucha meditación y critica sagaz, que da valor á la gramática de dicho autor, no muy conocida" (el subrayado es nuestro).

11 Curiosamente, en un cierto momento, Gómez de Salazar alude, de manera claramente irónica, a que la presencia de la lengua castellana como tema recurrente en el periódico viene dado por su deseo de ser académico ("Cada loco con su tema", EME, 25-XI-1873). 
En todo caso, más allá de todo esto, su influencia en El Magisterio español en los años en que ejerció como redactor provoca que los temas lingüísticos cobren especial relevancia en sus páginas. Este hecho es el que ha determinado los límites cronológicos de este artículo: dado que reconstruir las ideas lingüísticas y pedagógicas en el siglo y medio de vigencia de esta cabecera superaría con mucho los límites de este artículo, nos vamos a detener en el periodo $1871-1880^{12}$.

\section{LAS COLUMNAS SOBRE LENGUA EN EL MAGISTERIO ESPAÑOL ENTRE 1871 Y 1880}

Podemos encontrar una gran diversidad temática en los textos sobre la lengua publicados en el periodo; así, encontramos artículos sobre cuestiones gramaticales -que incluyen desde disquisiciones sobre el pronombre, la interjección o la existencia de la declinación a observaciones sobre el género de palabras concretas como 'tranvía' o 'bachiller', entre otros; de especial interés son las reseñas de obras gramaticales contemporáneas ${ }^{13}-$, columnas sobre aspectos ortográficos -en las que destacan especialmente las polémicas neográficas (vid. Gaviño, en prensa), pero también notas diversas en las que la ortografía, el uso lingüístico, se convierte en marca de instrucción o en

12 Durante la década que analizamos, el diario, con algunas variantes organizativas, publica una media de seis números al mes (aproximadamente 74 números por año), normalmente de unas cuatro páginas (según el periodo), organizadas en columnas. Se han revisado los fondos de la Biblioteca Virtual de Prensa Histórica (https://prensahistorica.mcu.es/) que recoge la totalidad de los números publicados entre 1871 y 1875; en 1876, los números publicados de mayo a diciembre y entre 1878 y 1880 , si bien se recogen números de todos los meses, no se encuentran la totalidad de los que se publicaron en la época. En total, se han revisado 567 números, que se corresponden con el $85 \%$ de los ejemplares que se debieron publicar, por lo que no descartamos la ampliación de los datos ofrecidos aquí. En ese periodo dirigió la publicación Emilio Ruiz de Salazar, quien sucedió a finales de 1868 al fundador, Mariano Carreras y González.

13 Especialmente significativas, por su repercusión y por las explicaciones lingüísticas que incluyen, son la crítica a los Elementos de gramática castellana de Avendaño (publicada el 15-VIII-1871), la crítica al Guía práctico de la enseñanza de la gramática castellana de José Mediavilla y Pidal (publicada el 20-V-1873) y que origina una larguísima respuesta del autor con comentarios de Gómez de Salazar entre los meses de julio y agosto de 1873 y la crítica a la Gramática castellana de Herráiz (publicada el 5-XI-1873), que da origen a una importante polémica sobre el pronombre. 
argumento de crítica $^{14}$ - y ortológicos ${ }^{15}$, textos sobre léxico -que reflejan la discusión en torno a las palabras "castizas" y los barbarismos, así como la función y valor otorgado al Diccionario académico, además de, como ocurre con la ortografía, convertir el uso de las palabras y su significado en argumento de ataque o defensa ${ }^{16}$-, artículos sobre enseñanza de la lengua en sentido amplio - vamos a encontrar tanto textos que abordan la enseñanza de la lengua en general, como cuestiones concretas, por ejemplo, sobre el análisis, así como aproximaciones a la enseñanza de las lenguas clásicas ${ }^{17}$ o notas sobre otras lenguas peninsulares-, y una diversidad de artículos y notas breves sobre aspectos diversos -i.e., sobre la situación lingüística en Japón ("No es fácil", EME, año VII, n. ${ }^{\circ} 303,25-I I-1873$ ), acerca de la presencia de la lengua española en el extranjero ("Difusión del castellano", $E M E$, año XII, n. $\left.{ }^{\circ} 715,15-\mathrm{XI}-1878\right)^{18}$, sobre la vida cotidiana de la Academia (por ejemplo, el 15-VII-1875 se habla de la creación de la correspondiente mexicana, además de publicarse infinidad de notas sobre las actividades de

14 Nos referimos a textos como "Un alcalde y su secretario. Modelos de instrucción" (año VI, n. ${ }^{\circ} 258,10-V I I-1872$ ) o "Modelo de comunicaciones oficiales" (año IX, n. ${ }^{\circ} 459,25$ IV-1875), en los que se denuncia el bajo nivel educativo de los alcaldes y funcionarios, por ejemplo, o el artículo "Vicios frecuentes en el idioma castellano" de Gómez de Salazar (año IX, n. ${ }^{\circ}$ 504, 10-XII-1875), donde se critica el mal uso del lenguaje de periodistas y escritores.

15 En esta categoría se incluyen el artículo "Cuestión ortológica" (Gómez de Salazar, EME, año X, n. ${ }^{\circ}$ 569, 5-XI-1876), sobre los sonidos de las letras, o la serie "De algunas locuciones viciosas del castellano", firmada por Alejandro Oliván, que se detiene en la pronunciación de palabras de origen griego y latino, principalmente (EME, año X, n. ${ }^{\circ} 535,15-\mathrm{V}-1876 ; \mathrm{n}^{\circ}$ $538,30-\mathrm{V}-1876 ; \mathrm{n}^{\circ} 539,5-\mathrm{VI}-1876$ y n. $\left.{ }^{\circ} 540,10-\mathrm{VI}-1876\right)$.

16 Además de los nombrados más adelante, destacan los artículos "Cada loco con su tema" (serie publicada los días 25 y 30 de noviembre y 5 de diciembre de 1873), sobre los extranjerismos; "El idioma español" (5-I-1873), sobre la riqueza del léxico castellano o "La Autoridad de la Academia" (publicada los días 10, 15 y 20 de marzo de 1875), en respuesta al discurso del mismo título de Galindo y Vera de entrada a la Academia (21 de febrero de 1875), todos de Gómez de Salazar, y la serie "Breves consideraciones acerca de la influencia de la lengua árabe en la castellana", de Ramírez y Laguardia (EME, año VII, n. ${ }^{\circ} 315$, 25-IV1873, n. ${ }^{\circ} 316,30-\mathrm{IV}-1873$ y n. $^{\circ} 317,5-\mathrm{V}-1873$ ).

17 Aunque, como se ha indicado más arriba, las lenguas clásicas pierden peso en el conjunto de artículos de temática lingüística registrados en el periodo 1871-1880 y solo se ha localizado un artículo destinado al latín, "Reflexiones acerca del estudio de la gramática, particularmente la latina", publicado por Vicente Calatayud y Bonamatí (EME, año XIII, n. ${ }^{\circ}$ 788, 20-XI-1879) y diversas reseñas y comentarios, a cargo, por lo general, de Ramírez y Laguardia.

18 Este tipo de artículos aportan interesantes datos sobre diarios y publicaciones en lengua española publicados fuera de los territorios hispanohablantes: "En Salónica se publica un periódico titulado La Época redactado en español é impreso en caracteres hebreos. Revisten idéntico carácter El Correo de Viena, en Viena, La Patria y El Nacional, en Constantinopla, y en general todos los diarios israelitas de la Turquía" (15-XI-1878). 
la Institución, informes emitidos sobre obras diversas, etc.), sobre el árabe ("Rudimentos del árabe", EME, año VI, n. ${ }^{\circ} 286,30-X I-1872$, publicado previamente en El Irurac-bat), o disquisiciones lingüísticas variadas como "Diversos sistemas de numeración que existieron en la Antigüedad"19, de José Marzán, tomado de El Magisterio de Ciudad Real (EME, año XI n. ${ }^{\circ}$ 624, 10-VIII-1877), entre otros.

En este trabajo, nos vamos a ocupar de la serie "Cuatro palabras sobre filología", de Gómez de Salazar, dado que consideramos que muestra de manera clara no solo las ideas lingüísticas de su autor, sino también la dirección que toma el periódico en la década analizada, y de los artículos sobre gramática y sobre enseñanza de la lengua que aparecen en $E M E$. Es digno de señalar que, si bien la mayoría de los textos sobre gramática son de Gómez de Salazar, no ocurre lo mismo con las columnas sobre enseñanza ${ }^{20}$. Una explicación a esto puede estar en el hecho de que, pese a que Gómez de Salazar fue autor de obras que podemos considerar didácticas o escolares, no se dedicó efectivamente a la docencia, más allá de algunas clases, en su vivienda particular, de gramática y de taquigrafía ${ }^{21}$ ( $c f$. Gaviño 2021). $\mathrm{Su}$ posicionamiento didáctico en torno a la lengua -si es que podemos denominarlo así- se orienta, por un lado, a rechazar el papel y el privilegio de la Academia como generadora de materiales de enseñanza (véase, por ejemplo, el artículo "Anarquía en la enseñanza", 20-VII-1871, o el mucho más revelador "Libros de texto", 10-III-1875, así como su artículo "¿Se enseña el castellano?", Los Lunes de El Imparcial, 13-VIII-1877)- y, por

19 Se trata de una explicación que alude a las denominaciones de los guarismos en los diferentes sistemas de numeración. "La lingüística", finaliza la columna, "nos revela claramente el origen de la numeración".

20 Sí que escribe, no obstante, algunos textos de temática didáctica general, como, por ejemplo, una sucinta explicación sobre los métodos de enseñanza (año VI, n. ${ }^{\circ} 223,15-1-1872$ ) o una serie de dos artículos titulada "La base de la enseñanza" (año IX, n. ${ }^{\circ} 649,15-X I I-1877$ y n. $\left.{ }^{\circ} 650,20-X I I-1877\right)$, destinada a reivindicar la importancia de la lectura y la escritura y la necesidad de la graduación de los estudios: "Como salió de la instrucción primaria sin saber leer bien, por más que lo haga de corrido, cuéstale ímprobo trabajo penetrarse de lo que dice el libro, y como además, apenas si conoce algo de gramática castellana, y el estudio del latin, por ejemplo, supone ya á los que á él se dedican, regularmente impuestos en aquella, de aqui que, aun queriendo alguna vez sacar de la lección el fruto debido, le sea imposible hacerlo á causa de la falta de conocimientos prévios que son de absoluta necesidad".

${ }_{21}$ Su interés por la taquigrafía le lleva a proponer su inclusión como materia de enseñanza en enero de 1876 en el artículo "Asignatura indispensable" y a discutir sobre el tema de nuevo dos años después ("La taquigrafía en la primera enseñanza”, 10 y 15 de enero de 1878). 
otro, a valorar la utilidad para la enseñanza de los textos lingüísticos que reseña, algo que, de nuevo, no está exento de cierto interés personal ${ }^{22}$.

\subsection{CUATro PALABRAS SOBRE FILOLOGÍA}

La primera serie lingüística localizada, "Cuatro palabras sobre filología", firmada por Gómez de Salazar, comienza a publicarse en la sección doctrinal en diciembre de 1870 y concluye en marzo de 1871 (15 entregas). Inicialmente, tal y como se señala en el epílogo, el autor aspiraba a enunciar "los principales idiomas de la raza humana, hablar con alguna detención de nuestra lengua patria, y demostrar tanto el desdén con que se mira su estudio, como el abandono en que se halla por los que tienen el deber de velar por su perfeccionamiento y brillantez" (EME, año V, n. ${ }^{\circ} 162,10$-III-1871).

Efectivamente, los dos primeros artículos se destinan a cuestiones sobre las lenguas del mundo desde la perspectiva de la lingüística comparada. Gómez de Salazar pretende dar una idea de la abundancia y la diversidad de las lenguas, si bien es consciente de las limitaciones no solo de sus conocimientos, sino también del medio en el que está escribiendo; pese a ello, no duda en detenerse en aspectos concretos del léxico para mostrar la riqueza y expresividad de alguna de las lenguas que aborda, como el visaya o la lengua de las Marianas. El carácter crítico del autor se muestra claramente cuando aborda el tema del número de lenguas del mundo, a través de las citas a Adelung ${ }^{23}$ y Balbi ${ }^{24}$, al que reprocha haberse "quedado corto" en su cómputo, precisamente por la división entre lengua y dialecto:

Fundándonos en que hay muchas y muy extensas comarcas cuyo lenguaje es desconocido a los europeos. De China, por ejemplo, ¿quién nos dirá el inmenso número de dialectos que allí se hablarán, por más que estos tengan grande analogia con el idioma chino, como en España sucede con el valenciano respecto del castellano? (EME, año V, n. ${ }^{\circ} 149$, 5-I-1871).

22 De la misma manera, sus obras aparecen reiteradamente en la sección de anuncios y se publican breves notas en las que se recogen las críticas favorables vertidas por otros diarios. Véase por, ejemplo, la que aparece el 25 de agosto de 1874 (año VIII, n. ${ }^{\circ} 411$ ), donde no solo se alude a los "vastos y profundos conocimientos del autor", sino que se recomienda "de modo muy especial a los señores Maestros para servirles de consulta" y se alude a no menos de trece publicaciones que la han elogiado y reseñado.

23 En el artículo, menciona su Catálogo de todas las lenguas y dialectos (Adelung 1815).

24 Se refiere a Balbi (1826). 
Para el autor, la progresión natural es el aumento del número de lenguas y considera utópica la idea de una lengua única, en referencia a la lengua universal, más allá que como medio de comunicación entre "los sabios de todas las naciones", apoyándose para ello en el nacionalismo, esto es, "el amor que cada cual profesa á su patria, á su lengua y á sus costumbres". En 1874, publica la columna "Lengua universal" en la que reitera esta idea:

Tiempo hace que se trata de inventar un idioma que sirva al principio de comunicacion entre los sábios del mundo, vaya luego extendiéndose por todas las naciones hasta hacerse el único ó por lo menos el predominante por medio del cual se entienda la raza humana abriendo de este modo una gran brecha á las murallas que mantienen la division entre las diversas nacionalidades. Lo primero no es difícil [...]. Lo segundo lo creemos materialmente imposible" (EME, año VIII, n. ${ }^{\circ}$ 377, 5-III-1874).

La columna en sí se destina inicialmente a resumir el prospecto de Lengua Universal de Andrés Dinelli y Aparicio ${ }^{25}$, profesor de lenguas y educación física en Madrid, si bien Gómez de Salazar, con cierta desconfianza hacia la propuesta de Dinelli, dedica la parte final del texto a comentar la Gramática de la lengua universal de Sotos Ochando (Madrid: Imprenta de J. Martín Alegría, 1863), obra que le merece una mayor consideración.

Tras esta introducción a las lenguas del mundo, pasa Gómez de Salazar a ocuparse de la lengua española y, después de una loa en los términos que habitualmente se emplean en la época (el castellano es superior a otras lenguas en fluidez y armonía, es flexible, etc.), plantea algunas cuestiones tipológicas en las que suscribe, sin mencionarlo, las doctrinas de Catalina del Amo (1861) sobre el semitismo de la lengua española -a la que considera neolatina en el nivel léxico, pero neosemítica en el plano gramatical-, aludiendo tanto al alfabeto (que retrotrae a los fenicios y hebreos al igual que Catalina 1861: 15) como a cuestiones morfosintácticas (formación del género femenino, del aumentativo, ausencia de caso y uso de las preposiciones o presencia del artículo) y, especialmente, al orden oracional: "si queremos traducir palabra por palabra un trozo latino guardando el mismo orden que

25 En el catálogo de la BNF aparece un prospecto de 8 páginas firmado por Dinelli en francés con el título Langue universelle gymnophisio-psychologie. Pages pour former un livre. Première brochure... (Paris: impr. de Marchand, 1876), que no tenemos la certeza de que sea el mencionado, que parece estar en castellano y se destina a describir el programa de la escuela madrileña del autor. Los periódicos de la época, incluido EME el 30-III-1875, recogen una noticia sobre el rápido aprendizaje de un alumno al utilizar el texto de la "ortografia universal y unificación poliglótica" de este autor, pero, hasta el momento, no se ha localizado nada más al respecto. 
tienen, nos resultará una especie de galimatias que no podremos comprender. Mas si el trozo, cuya version nos proponemos, es árabe ó hebrero, la obtendremos en buen castellano" (Gómez de Salazar, EME, año V, n. . 149, 5-I-1871 $)^{26}$. Estas ideas aparecen también en la serie firmada por Ramírez y Laguardia en 1873, "Breves consideraciones acerca de la influencia de la lengua árabe en la castellana", y entroncan con los planteamientos que en ese momento defienden los historiadores filósofos y filólogos de la Facultad de Letras de la Universidad Central como Francisco Fernández y González o el propio Catalina, quienes conciben la influencia semita como "elemento enriquecedor de la lengua, la literatura y, en general, de toda la cultura nacional" (Rivière 2000: 81) y, muy especialmente, la de los árabes, cuya contribución se considera un factor fundamental en la superioridad del carácter y la cultura española. Así lo expresa Ramírez y Laguardia:

En suma, en nuestro carácter, en nuestra lengua, en nuestras costumbres han dejado huellas imperecederas los árabes [...]. Basten ligeros ejemplos: en la vulgar frase hasta mañana, si Dios quiere, conservamos el providencialismo arábigo; en la de estamos buenos á Dios gracias, el espíritu profundamente religioso del pueblo mahometano; hasta en la fórmula cortés, de invitar á los presentes ó á los recien venidos á comer, cuando nosotros lo estamos verificando, se conserva el recuerdo de aquellas tribus árabes, cuyo xeque no se sentaba á la mesa sin hacer pregonar en voz alta que aquella estaba puesta para todo peregrino, cumpliendo con los sagrados deberes de la hospitalidad, tan en uso entre los pueblos antiguos y especialmente entre los pueblos semitas (EME, n. $\left.{ }^{\circ} 317,5-V-1873\right)$.

Esta tendencia se evidencia, asimismo, en las menciones en favor de la enseñanza de la lengua árabe que se encuentran en otros artículos ${ }^{27}$.

Más allá de esta indicación tipológica, Gómez de Salazar se centra completamente en lo que considera las causas de la decadencia de la lengua española. Ya en el segundo artículo de la serie, plantea algunas cuestiones

26 Dice Catalina al respecto: "Abrid un libro latino, de pura latinidad, y probad á traducir palabra por palabra; resultará una serie de dislates: haced el experimento con un libro hebreo ó árabe, y os resultará un castellano muy parecido al de Fray Luis de León" (1861: 29).

27 Así, por ejemplo, al informar de los datos estadísticos de la Universidad Central y hacer notar la mayor matrícula en la materia de hebreo que en la de árabe, se señala: "En efecto, sin negar la importancia del idioma en que están escritos los Libros Sagrados, creemos que la tiene muchísima entre nosotros la lengua que se habló en nuestro suelo durante largos siglos, en la que están escritas multitud de obras literarias de todo género [...]" (Ramírez y Laguardia, "Estadística académica", EME, año XIII, n. ${ }^{\circ} 771$, 25-VIII-879). 
que tienen que ver con su aprendizaje; así, si considera una ventaja el hecho de que "escribirse tal como se habla, ó de leerse tal como se escribe", ve dos escollos importantes: "sus muchos verbos irregulares ${ }^{28}$, y los infinitos giros intraducibles" algunos de los cuales considera "grandes disparates". Pero es en el tercer artículo (10 de enero de 1871) donde desarrolla plenamente la idea de que el castellano está en declive a consecuencia del abandono en que se encuentra su enseñanza, bien porque se ha dado preferencia al latín, bien porque la amplitud y diversidad de $\operatorname{contenidos}^{29}$ no permite que se dedique a su estudio el tiempo o la atención que, según el autor, merece:

¿Cuál podía ser el resultado, cuando el estudio de nuestra lengua no entraba para nadie en la espeluznante lista de estudios indispensables para el ingreso en cualquier carrera, ó cuando mas, se contentaban los examinadores con cuatro preguntas rudimentarias de gramática castellana? ¿Cuál había de ser? Que nadie se haya cuidado de lo que no se ha tenido por interesante. De aquí el que en las escuelas y colegios se haya mirado con tanta indiferencia que jvergüenza decirlo! Son pocos los que, aun despues de concluir sus estudios, saben leer y escribir en castellano.

Precisamente, el autor rechaza que el desarrollo correcto de las habilidades de lectura y escritura pueda hacerse únicamente, con "los escasísimos conocimientos gramaticales" que se aprenden en la escuela o "el monótono y arrullador canto del Catón o y el Amigo de los niños, ó la escasa instrucción que sobre esta materia se dá en la segunda enseñanza" y considera necesaria una mayor dedicación al estudio del idioma. No obstante, Gómez de Salazar no destina sus columnas a enunciar las vías para llevar a cabo estas acciones recuperadoras - más allá de recomendar a los padres de familia que proporcionen a sus hijos libros de buenos escritores-, sino que responsabiliza directamente a la Academia del "abandono [...] del idioma", con lo que abre

28 La cuestión de los verbos irregulares es especialmente importante para el autor, quien, además de usar ese aspecto como argumento de crítica a la Academia en diversos lugares (por ejemplo, en sus artículos de en El Imparcial), va a escribir un manual destinado a ellos, su Conjugación completa de todos los verbos irregulares castellanos, y de los defectivos en los tiempos y personas que están en uso (Madrid: J. M. Lapuente, 1873). El prólogo de la $1^{\mathrm{a}}$ edición se publica en $E M E$, en la sección bibliográfica (año VII, n. ${ }^{\circ} 306,10-I I I-1873$ ) y allí defiende la necesidad de esa obra con dos argumentos principales: el diccionario no recoge los verbos irregulares ni defectivos $-\mathrm{y}$, por tanto, no resulta de ayuda para resolver las dudas de los hablantes-y las gramáticas o bien no recogen la totalidad de los casos, o bien listan entre los irregulares verbos que no lo son.

29 Este mismo argumento emplea algunos años más tarde en su columna "La base de la enseñanza" (EME, año IX, n. ${ }^{\circ} 649,15-X I I-1877$ y n. $\left.{ }^{\circ} 650,20-X I I-1877\right)$. 
dos vías de crítica: al Diccionario, en las columnas publicadas el 15, 20 y 25 de enero, y a la Gramática, a la que destina las columnas publicadas entre el 30 de enero y el 10 de marzo.

Las columnas destinadas al Diccionario son una dura diatriba contra la Institución, al punto de que llega a afirmar que "hay fundado motivo para sospechar que el Diccionario ha sido hecho por delegados ó comisionados de [los académicos], algunos de los cuáles desconocían casi por completo el idioma castellano" así como "hoy por hoy no puede ser consultado [el Diccionario] sin desconfianza" (EME, año V, n. $\left.{ }^{\circ} 151,15-\mathrm{I}-1871\right)$. Gómez de Salazar encuentra muchas carencias en esta obra académica y considera que el uso debe ser el criterio fundamental para la inclusión de términos. Para él, nada es desdeñable en el enriquecimiento del idioma, ni siquiera los extranjerismos ${ }^{30}$; no obstante, cree que es responsabilidad de la Academia la labor de hacer propias todas las voces, incluso, de crear palabras cuando sea necesario:

Pero debia saber el respetable Cuerpo, que si la mision que tiene á su cargo, la obliga á no tomar del extranjero voces innecesarias por existir sus iguales castellanas, la riqueza del idioma exige que éste adopte todas aquellas que le falta, ya inventándolas, ya españolizando las extrañas. ¿Sabeis cuántas palabras extranjeras tiene el inglés? [...] dos quintas partes de dicha lengua. ¿Y qué hacemos los españoles? Carecer de infinitas palabras que el adelanto científico, artístico é industrial ha hecho necesarias, ó introducirlas en nuestro lenguaje tomándolas tal y como las hallamos en el extranjero, por no haberse cuidado la Academia en adoptarlas y españolizarlas (EME, año $\left.\mathrm{V}, \mathrm{n} .^{\circ}{ }^{\circ} 151,15-\mathrm{I}-1871\right)$.

En esta idea de la españolización de las voces, aparecen también argumentos morfológicos, como la necesidad de que la Institución dote de plural a palabras como yacht o álbum: "si la considera latina adopte, como los ingleses, el plural alba; si castellana, álbumes" (id.). La cuestión de los extranjerismos y términos nuevos y su ajuste a las características de la lengua española surge también en otros artículos, en los que se realizan interesantes reflexiones metalingüísticas, como es el caso del destinado a la palabra tranvía, "Tramvía el ó la", que suscita una discusión sobre su género y su uso en construcciones (Gómez de Salazar, EME, año V, n. ${ }^{\circ} 183,25-\mathrm{VI}-$

30 No obstante, no hay que pensar que el periódico ni sus redactores se muestran partidarios de la introducción de términos extranjeros en el idioma, tal y como se muestra claramente, por ejemplo, en la serie, firmada por Gómez de Salazar, "Cada loco con su tema”, publicada los días 25 y 30 de noviembre y 5 de diciembre de 1873 . 
$1871)^{31} \mathrm{o}$, en menor medida, al hilo del anuncio de la primera mujer en cursar Bachillerato en España, $\mathrm{M}^{\mathrm{a}}$ Elena Maseras, se indica, no sin cierta ironía, "confiamos en que no será bachillera" -recogido en el Diccionario de la Academia como "La mujer que habla mucho, ó sin concierto ni oportunidad" (RAE 1869)- "sino bachiller hembra" (EME, año VI, n. $\left.{ }^{\circ} 259,15-\mathrm{VII}-1872\right)$.

En las columnas siguientes de "Cuatro palabras sobre filología" (20 y 25 de enero), el autor va dando ejemplos de voces de las que carece el castellano y cuáles podrían ser las que se podrían adoptar (i.e. "remitente"), de palabras de las que no se incluyen todas las acepciones, como "paralizar" o "relacionar" ("¿Ignora el venerable Cuerpo que esta palabra tiene otra acepcion muy principal que nos calla sin saber por qué? ¿No sabe que relacionar es poner en relación una persona ó cosa con otra?", EME, año $\mathrm{V}$, n. $^{\circ} 152,20-\mathrm{I}-1871$ ), de algunas que incluyen acepciones que, según el articulista, no poseen, como "Hablado.- El que habla", o, directamente, de acepciones erróneas, como es el caso de "Desafear.- Deformar, afear alguna cosa". Asimismo, va rechazando aspectos concretos en otras voces, como, por ejemplo, al hablar de "cabriolé", que la Academia indique que lo usan hombres y mujeres o en la definición de "bocado", que se hable de "porción de alimento" y no de "porción de comida" (año V, n. 153, 25-I-1871). Los argumentos, especialmente los que se dan en relación con las definiciones inexistentes o equivocadas, van desde enunciar frases con las acepciones propuestas para mostrar, mediante la burla y la interpelación directa al lector, lo erróneas que resultan, hasta, como ya ocurría con los extranjerismos, aludir a cuestiones morfológicas, como el valor del prefijo des- en la formación de palabras para el caso de "desafear".

Estas columnas no van a ser el único lugar donde se señalen las carencias del Diccionario académico, aspecto que aparece en diferentes artículos publicados en $E M E$, al hilo, habitualmente, de otras cuestiones (i.e. "Corrección en el lenguaje", EME, año VI n. $\left.{ }^{0} 268,30-\mathrm{VIII}-1872\right)^{32}$. En

31 Gómez de Salazar es partidario del género femenino y para sustentar su propuesta, dado que la palabra 'tramvía' no está recogida en el diccionario, analiza tanto el uso que se está haciendo de dicha voz en la prensa (en La Constitución, concretamente), como su etimología. Esta columna origina una serie de comentarios, como la nota sin título, publicada el 5 de julio de 1871 que recoge la respuesta de La Constitución al artículo apoyando la teoría de EME, y las diferentes contestaciones de Gómez de Salazar a las críticas sobre su columna vertidas desde El Naturalista, con un tono muy beligerante y bastante alejadas del tópico inicial (véase, por ejemplo, "Un Tetragramaton", EME, año V, n. $\left.{ }^{\circ} 214,30-X I-1871\right)$.

32 Gómez de Salazar se ocupará del tema de nuevo ese mismo año en su Juicio crítico del Diccionario y de la Gramática últimamente publicados por la Academia Española exponiendo los muchos y gravisimos errores que ambas obras contienen (Madrid: Gregorio Fuste 1871) 
general, lo que se pone en primer plano -al igual que ocurre con la crítica a la ortografía- es, como ya señaló Buzek (2014), la función normativa y normalizadora de la Academia de la cual depende, en opinión del autor, el propio prestigio de la lengua.

Algo distinto, pese a lo que se indica en las columnas, es el planteamiento en torno a la Gramática, donde se deja de lado esta cuestión del uso de la lengua y se dedica la crítica a cuestiones doctrinales en las que se discrepa con la Academia; esto es, aspectos relativos al tratamiento y definición de las categorías gramaticales (tópico en torno al que giran principalmente las columnas) en los que los manuales gramaticales publicados por el autor (1869, la Gramática y 1870, el Compendio) difieren del texto académico, como, por ejemplo, la definición de artículo o nombre, la clasificación del verbo, el tratamiento de los tiempos verbales o las reglas del régimen, entre otros. Un ejemplo de cómo se orientan estos artículos es el tratamiento dado al adjetivo (EME, año $\mathrm{V}$, n. $\left.^{\circ} 155,5-\mathrm{II}-1871\right)$ : por una parte, se critica a la Academia la denominación empleada, "adjetivo", ya que no responde a la función que, para él, desempeña esa categoría gramatical, que es la de calificar - de ahí, que en su gramática, esta parte de la oración se denomine "calificación"- y por otra, estrechamente ligada a lo anterior, se rechaza la posibilidad de que el adjetivo pueda realizar cualquier otra función que no sea la de calificar, significativamente, la de determinar. Esto es, la Academia define el adjetivo en su edición de 1870 como "aquella parte de la oracion que se junta á los sustantivos para calificarlos ó determinarlos" (p. 33) y, a partir de esa definición los divide en calificativos y determinativos, "que sirven para determinar la extension en que se toma el significado del sustantivo" (id.). Para Gómez de Salazar, la función de determinación plantea un problema evidente, dado que por un lado, los artículos determinan con lo que habrían de ser considerados adjetivos y no lo son; $\mathrm{y}$, por otro, no considera que haya palabras que califiquen y determinen al mismo tiempo, por lo que el único factor que permite unir ambos tipos bajo la categoría adjetivos es su posición adjunta al nombre, aspecto que rechaza por considerar que el resto de partes de la oración también se posicionan junto al nombre. Un último argumento que esgrime, aunque no desarrolla, es el de que los calificativos no pueden funcionar solos en la oración, pero, por el contrario, los determinativos pueden transformarse en pronombres, con lo que esboza uno de los aspectos

que es una reiteración de las ideas expuestas en $E M E$ y unos años después publicará sendos artículos al respecto en La Ilustración Española y Americana bajo el título "El Diccionario de la lengua castellana por la Real Academia Española" (n. ${ }^{\circ} 13,8$-IV-1878 y n. ${ }^{\circ} 15,22-I V-$ 1878) (vid. Jiménez Ríos 2013). 
-el de los límites entre el pronombre y el adjetivo-, que va a tener un lugar central en las polémicas gramaticales que se suscitan en el periodo ${ }^{33}$.

Se observa, pues, la diferencia, que aparece también con posterioridad en otros artículos de $E M E$, entre las columnas dedicadas a la gramática y las que se destinan a las cuestiones léxicas (y también las ortográficas); estas últimas se sitúan claramente en un plano de demanda a la docta Institución de responsabilidad para que acometa las reformas que son consideradas necesarias por el redactor, dado que no puede ser una cuestión de un individuo, pues afecta, como ya se ha indicado, a la construcción social de la lengua y, por tanto, a su prestigio. Ahora bien, la Gramática se sitúa en otro plano de menor impacto social, el de la descripción científica del funcionamiento del idioma (se deja de lado cualquier aspecto prescriptivo), en el que el autor se siente libre para exponer sus propias ideas; "para nosotros" dirá unos años después, "no tiene valor ninguno el Magister dixit y no reconocemos otra autoridad que la de la razón" (EME, año VIII, n. ${ }^{\circ} 405$, 25-VII-1874). Esto se aprecia claramente en el prólogo de su Compendio de 1870: "Si en la Analogía y Sintáxis hicimos una gran reforma, fué porque de ella no podía resultar ningún mal á quien las aprendiera por nuestro método y sí mucho bien, pues ella solo alcanza á las reglas, y no á la esencia del lenguaje" (p. VII).

En esa misma línea, la serie de artículos concluye: "Despues del eáxmen (sic) que queda hecho de la Gramática de la Academia Española ¿habrá todavia Maestros que pasen por ilustrados, que la sigan teniendo de texto en sus escuelas? ¿No temerán la nota de rutinarios, enemigos de todo adelanto" (EME, año V, n. ${ }^{\circ} 162,10-$ III-1871) ${ }^{34}$.

33 Además de la polémica surgida a raíz de la reseña de la Gramática de Herráinz en EME, entre finales de 1873 y mediados de 1874, encontramos en la sección de Filología de la revista La idea en 1873 un debate interesante, tanto por su profundidad teórica como porque en él los contendientes son Joaquín Manuel de Moner, director del Instituto de segunda enseñanza de Fonz (en los números 17 y 18) y el eminente hebraísta Antonio M. García Blanco (que se publican en los números 21 y 23 ) sobre el estatus de artículos, pronombres y adjetivos. Asimismo, el tema de mío, tuyo y suyo, concretamente, vuelve a aparecen en la prensa diez años después en el Boletín de primera enseñanza de la provincia de Gerona (año X, n. ${ }^{\circ} 44$, 11-XI-1884), donde se reproduce un artículo de La Educación de Ferrer y Rico sobre el tema. Vuelve a reaparecer con el título "Una cuestión gramatical" en la Gazeta del Magisterio en 1898, que se hace eco de la publicada en el Diario de Reus (29-V-1898), con un comentario firmado por un tal A.M.

34 El autor pretende, como ya se ha afirmado en otros lugares de este trabajo, reivindicar su propia obra gramatical oponiéndola al texto académico y, de hecho, ese trabajo de enmienda y mejora-que aparece de manera reiterada tanto en su Gramática como en su Compendio-es lo que justifica en gran medida su valor; la aparición de una nueva obra gramatical por parte 


\subsection{GRAMÁTICA CASTELLANA}

La gramática castellana, junto con la ortografía, son los dos tópicos centrales en el periódico en el periodo analizado debido al interés personal de Gómez de Salazar en ambas cuestiones. Entre los diferentes aspectos que aparecen, tres van a ser centrales: el debate sobre la significación y clasificación de los pronombres, la cuestión de la declinación y el estatus de la interjección.

Sobre el pronombre, además del artículo dedicado a él en la serie "Cuatro palabras sobre filología" (año V, n. ${ }^{\circ} 156,10-I I-1871$ ), Gómez de Salazar publica un artículo titulado "Sobre el pronombre personal el y ella en dativo y acusativo" (EME, año VI, n. ${ }^{\circ} 247$ 15-V-1872) y la serie de artículos denominados "Cuestión gramatical" ${ }^{35}$, que responde a la polémica sobre la significación y clasificación del pronombre posesivo que se produce entre diciembre de 1873 y junio de 1874, principalmente entre Gómez de Salazar y los gramáticos y profesores Gregorio Herráinz y Millán Orío, quien escribe desde $L a$ Idea y en la que participan de manera anexa un buen número de cabeceras como La Revista de Huesca, El Magisterio Aragonés, La Imparcialidad, La Primera Enseñanza, El Ateneo Lorquino o El Consultor Riojano, entre otros.

El primer artículo es una interesante reflexión sobre el uso de los pronombres lo, la y le como acusativos y dativos que sigue los planteamientos antes esbozados: para Gómez de Salazar, el factor que debe determinar si un fenómeno gramatical dado en la lengua es correcto o no es el propio uso, "juez árbitro del lenguaje [que] no admite lógicas, y solo es ley su capricho", o más concretamente, el buen uso, más allá de lo que indique la Academia:

Contra el uso no hay razones entendibles, y no hay más remedio sino someterse á él muy de buen grado. Pero no se entienda por el uso el de los más en número, sino el de los más en ilustración. El uso de

de la Institución le obliga a volver a justificar dicho valor frente a su público: "En la edición anterior había un párrafo lleno de errores que combatimos en nuestra Gramática. Mas como sin duda la Academia se tiene por infalible, no advierte que llevando sus ojos tan elevados al cielo, pega veinte mil tropezones más que si los inclinára un poquito al suelo para ver por donde anda" (EME, año V, n. $\left.{ }^{\circ} 156,10-\mathrm{II}-1871\right)$.

35 Con el mismo título, se publican en 1876 dos artículos que se destinan al análisis; el primero de ellos (EME, año X, n. ${ }^{\circ} 539,5$-VI-1876) recoge la consulta de un maestro de Primaria sobre el análisis gramatical realizado en un acto académico (no se especifica cuál) y en el número siguiente (EME, año X, n. ${ }^{\circ}$ 540, 10-VI-1876) la respuesta de Gómez de Salazar, en la que el autor se detiene, de nuevo, en el pronombre como elemento conflictivo del análisis. 
aquellos generalmente es defectuoso, y por consiguiente solo el de los buenos hablistas y escritores es el que, constituyéndose en rey absoluto del idioma, lleva por nombre el buen uso. Como éste es el único juez competente en la materia que tratamos á él apelaremos, no sin antes hacer constar que la Academia Española admite en acusativo tanto al le como al $l o$.

El artículo ofrece muestras de diversos autores (desde Cervantes a Reinoso, pasando por Jovellanos, Iriarte, Espronceda o Quintana, entre muchos otros) que emplean le en función de complemento directo, lo que para el autor es aval indiscutible para aceptar ese uso, si bien es plenamente consciente de que es un fenómeno de la lengua sujeto a la variación: frente a lectores para los que "esta cuestión es clara como la luz", lectores que defienden lo contrario. No ocurre lo mismo con el empleo de la en función de complemento indirecto, condenado tanto por la gramática (aquí el autor rechaza la postura de Salvá y suscribe la de la Academia), como por el buen uso (de nuevo, se recurre a ejemplos de autores consagrados).

El otro asunto determinante sobre el pronombre, que ya aparece en "Cuatro columnas sobre filología", es el relativo al estatus gramatical de las voces mío, tuyo y suyo. Ya en ese primer artículo, el 10 de febrero de 1871, Gómez de Salazar deja clara su postura: estas voces no son sino verdaderos pronombres, incluso aunque acompañen al sustantivo, dado que considera que son las formas de genitivo de los pronombres personales yo, tú y él. La cuestión se torna en polémica tras la publicación, en la Sección bibliográfica de $E M E$ el 5 de septiembre de 1873, de la reseña de Gómez de Salazar de la Gramática castellana teórico-práctica en todas sus partes, publicada por Gregorio Herráinz en 1869 (Madrid: Imprenta de la Monarquía Democrática). En ella, se censura, precisamente, que Herráinz, acorde con la doctrina académica (que solo los agrupa entre los pronombres "por tradición"), niegue el valor pronominal de las formas posesivas mío, tuyo, suyo y las considere adjetivos. Ambos autores se enzarzan a partir de ahí en un intercambio de argumentos en las páginas de $E M E(20,25$ y 30 de enero y 28 de febrero de 1874$)^{36}$, aludiendo tanto a la significación como a la equivalencia de esas formas para sostener su postura. La entrada de un nuevo contrincante, Millán Orío ${ }^{37}$ el 2 de marzo de 1874 desde el periódico

36 La última réplica de Herráinz a Gómez de Salazar se realiza desde La Idea, el 16 de marzo de 1874.

37 Para Orío, tiene diferentes valores: como adjetivos determinativos posesivos y como pronombres posesivos y aún añade un tercero, el de personales derivados. 
La Idea, da un giro al, hasta ahora, debate amable, y lo transforma en un enfrentamiento de carácter bélico que se extiende entre marzo y mayo de 1874 y que pasa a centrarse, en gran medida, en el valor del genitivo y en sus formas de expresión en castellano ${ }^{38}$. Asimismo, en estos textos, se alude a los demostrativos, que también oscilan entre los adjetivos y los pronombres. No obstante, algo interesante en el tratamiento dado por Gómez de Salazar a la cuestión es que, de nuevo, pretende trascender los límites de la gramática en cuanto que ciencia y situarse en el plano del uso, como muestra la diferencia que establece entre este aspecto y la cuestión de los demostrativos:

Las cuestiones que hemos tratado en el artículo anterior afectan solo á la parte científica de la Gramática, pero de ningún modo á su objeto que es el de hablar bien. Nada importa en efecto al lenguaje que á las palabras este, ese, aquel, etc. se las llame por unos, adjetivos, por otros, artículos, por otros, pronombres, etc., etc., puesto que tales denominaciones en nada hacen variar su uso en el lenguaje. No es así en la que hoy vamos á ocuparnos, pues si bien á primera vista parecerá que es de la misma índole que aquellas, nos proponemos demostrar que, por la inversa, es de importancia suma, no solo para la parte científica de la gramática, sino para el idioma mismo (EME, año VIII, n. ${ }^{\circ} 370$, 30-I-1874).

Efectivamente, para el autor es un error claro, que él mismo reconoce haber cometido, considerar de mí y de ti como formas de genitivo de los pronombres personales yo y tú, porque no responde al uso de la lengua:

De mí y de ti no caben en buen castellano mas que en ablativo. Se dice, por ejemplo, habla de mí, habla de ti, y aquí esos pronombres están en ablativo. Pero ¿es buen castellano libro de mí, sombrero de ti? No, en manera alguna; sino libro mío ó mi libro, sombrero tuYo ó tu sombrero. ¿Nos podrá citar la Academia, ni nadie, siquiera un ejemplo de buena locución en que hallemos de ti, de mí en genitivo? (EME, año $\mathrm{V}, \mathrm{n}^{\circ}{ }^{\circ} 156$, 10-II-1871).

Para demostrar rotundamente y en poquísimas palabras que eso es un grandísimo error, y que no hay tal de mí ni de ti en genitivo, bastaría hacer a todos los gramáticos la misma pregunta que á V. hice, y fue la siguiente: ¿HABRÁ ALGUIEN QUE NOS PRESENTE UN EJEMPLO DE BUENA LOCUCION

\footnotetext{
38 No vamos a abundar en los aspectos doctrinales de la polémica, dado que nos estamos ocupando por extenso de ella, junto a Garrido Vílchez, en otro lugar. Asimismo, un abordaje de ella, atendiendo especialmente a las cuestiones discursivas, puede verse en Gaviño (en prensa).
} 
EN Que hallemos las voces DE MI, DE TI, DE SI, Como Genitivos DE LOS PRONOMBRES PERSONALES? (EME, año VIII, n. ${ }^{\circ} 370,30-$ I-1874).

Un aspecto que ya aparece en estos textos es el relativo a la existencia de la declinación en castellano, de nuevo, cuestión en que Gómez de Salazar se va a situar como opositor de la doctrina académica, que solo reconoce la existencia de la declinación en castellano en los pronombres personales.

Aunque lo plantea ya de manera tangencial en "Cuatro palabras sobre filología", destina un artículo, "Sobre la declinación del nombre en castellano y sobre la interjección” ( $E M E$, año VIII, n. $\left.{ }^{\circ} 383,5-I V-1874\right)^{39}$, a tratar el tema, en respuesta a las demandas de otras cabeceras, como La Imparcialidad, surgidas al hilo de los artículos sobre el pronombre. Para el autor es indudable la necesidad de incluir la declinación en la explicación gramatical, dado que considera que, lejos de tratarse de un asunto puramente morfológico, es imprescindible recurrir a los casos para expresar las relaciones sintácticas:

Si no se enseñan las distintas maneras de que un nombre puede jugar en la oracion ¿cómo es posible hablar ni una palabra de sintaxis? Y si esta falta ¿cómo hablar de Gramática? Y si solo se concede declinacion á los pronombres personales ¿cómo se sabrá hacer la sustitución suya por el nombre, puesto que para ella se ha de poner á este en el mismo caso que tiene el pronombre? Véase, pues, cuán errados están los que defienden que no hay declinación en nuestro idioma, por haberse encerrado en la falsa idea de que significa variacion de desinencias (EME, año VIII, n. $^{\circ}$ 383, 5-IV-1874).

En el artículo despliega toda una serie de argumentos al respecto, tanto en relación con la idea de que la declinación equivale a variación desinencial-lo cual conllevaría, en su opinión, que el verbo también se declinase-, como en relación con los aspectos sintácticos, que avala desde la explicación etimológica del metalenguaje ${ }^{40}$. Por último, un argumento indiscutible, en

39 Este artículo motiva dos breves respuestas de Gómez de Salazar ante las críticas recibidas desde La Luz de Pontevedra y de "dos articulistas de periódicos", publicadas respectivamente el 20 de abril ("Abajo el magister dixit"), y el 5 de julio ("Pasmoso invento") de ese mismo año, ambas de poco calado teórico.

40 "[L]ejos de significar la variación de terminaciones, que no declinan, que no bajan, manifiesta claramente que el nombre que se halla en nominativo, va declinando (bajando, descendiendo) desde el puesto de agente ó sujeto de la oracion hasta llegar á ser un mero complemento de ella que hasta puede ser supérfluo" (EME, año VIII, n. ' 383, 5-IV-1874). De igual manera aborda el término "caso" y las denominaciones de cada uno de los casos. 
su opinión, para mantener la declinación es el hecho de que la variación funcional es coyuntural al nombre y

existe de necesidad en todos los idiomas conocidos, y no es posible inventar ninguno que carezca de nombres y que estos no funcionen unas veces como agentes, otras como pacientes, etc., etc., de aquí que la declinación del nombre sea tan inseparable del idioma como la luz solar del astro que la emite $(i d)$.

Ese mismo artículo se destina en la segunda parte a impugnar la doctrina académica sobre la interjección ${ }^{41}$. Asimismo, sobre esta cuestión, publica una serie de tres columnas en la sección doctrinal con el título "Las interjecciones" ( 25 de julio, 30 de julio y 10 de agosto de 1874 ) y una nota extensa en la sección orgánica (con el título "Interjecciones aun"), el 20 de septiembre.

Para el autor, es falsa la premisa sostenida por la Academia de que la interjección es una oración:

La interjeccion es una voz con que expresamos, por lo comun repentina é impremeditadamente, la impresion que causa en nuestro ánimo lo que vemos ú oimos, sentimos, recordamos, queremos ó deseamos. Por consiguiente, las interjecciones, más bien que partes de la oracion, son oraciones enteras: un $A h$ ! ¡Oh! equivalen á Estoy admirado, Estoy sorprendido, etc. (RAE 1870: 163).

El rechazo a esta idea le lleva, por un lado a impugnar la primera parte de la definición, aludiendo a que, si es oración la interjección por el hecho de ser expresiva, lo mismo se podría decir de los puntos suspensivos o de "la mirada de unos ojos negros y apasionados [...] que es todo un discurso que ni de Castelar" y argumentando que la Gramática no trata de explicar las emociones, sino las palabras:

Pero ese discurso, lo mismo que aquella oracion NO SE HAN EXPRESADO CON PALABRAS, y la gramática no puede alcanzar á oraciones ni á discursos MENTALES. La gramática no puede dar reglas para el habla intelectual, espiritual más bien, si este no se traduce en PALABRAS, único terreno á que su dominio alcanza. Y como en el lenguaje hablado no es posible la

41 No se alude a esta categoría en "Cuatro palabras sobre filología", pero su problematización posterior en las páginas de $E M E$, de nuevo, responde al hecho de que es un asunto que incorpora a la segunda edición de su gramática, publicada en 1874 (se incluye el prólogo de esta obra en la Sección bibliográfica el 20 de junio de ese año). 
oracion sin verbo, en un ¡Ay! ó en un ¡Oh! No hay tal oracion sino una sola palabra, que no es verbo, y que por significa que sea NO PODEMOS TRADUCIR (EME, año VIII, n. ${ }^{\circ} 383,5$-IV-1874).

Por otro lado, el autor se centra en demostrar lo erróneo que resulta el sistema propuesto por la Academia de hacer equivaler la interjección a una oración. Esta es la cuestión sobre la que va a organizar la serie "Las interjecciones", a partir de su interpelación a El Correo del Magisterio y El Magisterio Aragonés: “¿tendrían la bondad estos apreciables colegas de ponernos siquiera un ejemplo, no pedimos más que uno, de alguna de esas interjecciones que según ellos son oraciones elípticas y de expresar las palabras que por la figura Elípsis se han omitido en ellas" (EME, año VIII, n. ${ }^{\circ} 402$, 10-VII-1874). El autor deja de lado el debate doctrinal con esas cabeceras, al menos al principio, y procede a analizar los ejemplos de interjecciones propuestos y las equivalencias planteadas intentando demostrar que no es posible recurrir a la elipsis, pues la restitución de los elementos que supuestamente faltan en esa oración equivalente está abierta a la interpretación, bien por las características del hablante ${ }^{42}$, bien por los aspectos derivados del contexto ${ }^{43}$ y eso, para él, no es gramática:

[L]os que han dicho que las interjecciones son oraciones complejas y epopeyas, etc., etc., no las han visto con los ojos del gramático. La Gramática es muy árida, muy prosaica y no puede ni debe interpretar las palabras bajo el punto de vista de la poesía" (EME, año VIII, n. ${ }^{\circ} 406$, 30-VII-1874).

Para el autor, la gramática se aleja de la poética y la retórica, precisamente, en el modo objetivo con el que se observa la lengua, como para el doctor que asiste a una bella y virtuosa dama esta no es "otra cosa que la materia deleznable de nuestro ser, y le aplica el bisturí y las sustancias cauterizantes como lo haría con una perdida" (id.). En estas palabras, observamos algo

42 “Habéis visto algun ejemplar de azufre cristalizado? Es precioso: nosotros hemos visto recientemente uno que se vendía por mil reales. Para un mineralogista es una verdadera alhaja; pero llevadlo á un fabricante de pólvora ó de pajuelas, si hoy se usaran, y por ese precioso ejemplar os daría cuatro ó seis cuartos; para él no hay allí nada más que un trozo de azufre" (EME, año VIII, n. $\left.{ }^{\circ} 406,30-\mathrm{VII}-1874\right)$.

43 "Quitad de ese sepulcro ese ¡¡Ay!! Y trasladadlo á las súcias paredes de una cocina ó de un figon, y traducidme esa epopeya, si es que aun alli la hallais [...] ¿No es lo mismo ¡iAy!! en todas partes? ¿Cómo es que no se dice lo mismo aquí que allí? ¿Por qué? Porque no es ese ¡iAy!! El que habla, sino el sepulcro, en el cementerio, las paredes de la cocina [...]. Estos son los que hablan y le dan ó le quitan su importancia y su significacion á ese ¡¡Ay!!” (id). 
que se esboza también anteriormente: Gómez de Salazar concibe su labor desde una posición marcadamente positivista, esto es, la gramática como ciencia que busca las respuestas en la solidez de los datos. El último artículo de la serie, el 10 de agosto ${ }^{44}$, refuerza nuestra interpretación: a través de ejemplos, esto es, aportando datos, el autor demuestra que la expresividad no es exclusiva de la interjección, sino que el resto de las categorías gramaticales también pueden cargarse de esos valores expresivos, pero insiste en que atender a dichos valores no es función del "gramático no poeta", y, además se alejaría del deseado orden que demanda la ciencia:

[A]unque se quisiera establecer una diferencia entre las palabras por su significación ¿dónde hallaríamos la meta divisoria entre unas y otras, y donde el instrumento graduador de significaciones para determinar si tal palabra en ciertos y determinados casos se había hecho ya digna de ascenso en categoría? ¿Y dónde en fin la clasificacion de esos datos?

\subsection{ENSEÑANZA DE LA LENGUA}

Pese a ser una publicación de orientación profesional, no abundan en EME los artículos destinados a la metodología de la enseñanza de la lengua castellana, en general, o sobre aspectos de didáctica de la gramática en particular ${ }^{45}$ y los que hay, como ya se indicó, no son autoría de Gómez de Salazar.

44 En ese artículo también se ocupa de desmontar lo que considera una contradicción por parte de El Correo del Magisterio, quien en su artículo del 30 de junio, tal y como se recoge en la columna de Gómez de Salazar, había señalado que "no todas las interjecciones son oraciones, y las que hay no merecen el nombre de palabras ni por consiguiente el de partes de la oracion, sino que deben considerarse como se considera á las miradas, gestos, y ademanes" (EME, año VIII, n. ${ }^{\circ} 408,10-$ VIII-1874). Ya finalizada la serie, el 20 de agosto (n. $\left.{ }^{\circ} 410\right)$, el autor dedica un espacio en la Sección orgánica para responder al redactor de El Magisterio Aragonés, J. Agustín Alda, aunque se trata, sobre todo, de señalar las inconsistencias en la exposición de ese autor.

45 Dejamos de lado en este trabajo las cuestiones relacionadas con la lectura y la escritura y sobre la enseñanza a los sordomudos. Tampoco nos vamos a detener en la cuestión de las lenguas extranjeras, tema que, curiosamente, apenas se aborda en el periodo, más allá de algunas reseñas, como por ejemplo, la del Método Ollendorf adaptado á la correspondencia inglesa mercantil de Lorenzo Reynal (EME, año VII, n. ${ }^{\circ} 330,10-\mathrm{VII}-1873$ ) o la del Nuevo método para aprender el idioma alemán, según el sistema de Ahn, de Camilo Vallés (EME, año IX, n. ${ }^{\circ} 44,25-\mathrm{I}-1875$, ambas de Gómez de Salazar), así como algunas notas y textos esporádicos, como la carta al director, firmada por E.M., sobre la necesidad de cátedras de lenguas vivas en los Institutos de $2^{\mathrm{a}}$ enseñanza ("Lenguas vivas", año XII, n. ${ }^{\circ} 700,30$-VIII1878). 
Cabe resaltar varios aspectos sobre la presencia de la didáctica de la lengua en $E M E$ : en el aspecto externo, en primer lugar, son muy pocas las columnas que se destinan con exclusividad a ello y, en segundo lugar, abunda la traducción de artículos publicados en otras lenguas. Por otra parte, desde la perspectiva interna, se detecta un posicionamiento en los planteamientos de la enseñanza intuitiva que postulan una enseñanza reflexiva de la lengua, sin plantear en ningún caso el abandono de la gramática ${ }^{46}$, y la vinculación, en cierta medida, con las teorías gramaticales de raigambre filosófica (véase García Folgado 2019 y 2020).

Esto ya se aprecia en la nota titulada "Gramática", firmada por J. Agustín Alda, que aparece en la sección orgánica el 15 de marzo de 1874 (EME, año VIII, n. ${ }^{\circ}$ 379) en la que se reflexiona brevemente sobre la formación gramatical que los maestros reciben en las Escuelas Normales. Para Alda, la Gramática es "una de las materias que forman, por así decirlo, el núcleo de nuestra profesión" y rechaza un planteamiento que la aborde de manera mecánica y rutinaria y no centrado en "los principios filosóficos sobre los que descansan todas las lenguas" y en las "leyes de las palabras". El autor se centra en los ejercicios de oposiciones, en los que la gramática es, según sus propias palabras, "el barómetro más infalible del mérito relativo de los opositores" y, en concreto, en el análisis lógico, "parte tan embrollada y tan importante de nuestra ciencia Gramatical", que, para él, es "el escollo donde vienen a estrellarse por fin muchos jóvenes". Ciertamente, de las dificultades que los ejercicios de análisis presentan para los opositores en general y para los aspirantes al Magisterio en particular, da cuenta la prensa

46 Gómez de Salazar, en su columna "¡Abajo la gramática!” (EME, año XI, n. ${ }^{\circ} 630$, 10-IX-1877), ataca la idea que José Fernández Bremon expone en La Ilustración Española y Americana (año XXI, n. ${ }^{\circ} 32,30-\mathrm{VIII}-1877$ ) en respuesta al artículo del propio Gómez de Salazar publicado en Los Lunes de El Imparcial, “¿Sirve la gramática de la Academia para enseñar [el castellano]?" (20-VIII-1877) -he aquí una clara muestra de uno de los "ciclos polémicos" de los que habla Durán (2018)-, acerca del papel menor de la gramática en el dominio idiomático: "hoy necesita el hombre para hacer un papel mediano en la sociedad, estudios muy variados que invierten casi toda su vida, sin permitirle dedicarse profundamente á un estudio que la práctica y la lectura le dan hecho, á lo menos para el uso corriente y natural", dice Fernández Bremón. El firme rechazo de Salazar a esta idea es también una defensa, en gran medida, de la función de la Academia, y -al igual que ocurre en la polémica sobre la reforma ortográfica (Gaviño, en prensa)- muestra la tensión entre la oposición a la Institución por fines personales y el respeto al lugar de la misma en el plano social. Esto se ve muy bien en la nota publicada el 15 de febrero de 1877 (año XI, n. ${ }^{\circ}$ 589) en la que se responde a un "colega (y de instrucción)" quien critica que la Academia haya ordenado la separación del dígrafo - $r r$ - a final de renglón, a lo que contesta el redactor de $E M E$ : "El colega ha soñado. Lo que dijo en la Gramática de la penúltima edición, fue que adoptaba la regla, por si el uso la sancionaba $[\ldots] "$. 
especializada reiteradamente y se publican artículos, así como manuales, orientados a su desarrollo (vid. García Folgado 2012 y Montoro del Arco $2019)^{47}$. En el caso de Alda, tanto para la realización de los ejercicios de análisis de las oposiciones como el aprendizaje gramatical en general, es necesario que la formación de los maestros se oriente, por un lado, al conocimiento de las teorías gramaticales, en plural, y al entendimiento "del fundamento de las razones en las que las apoyan [los autores]" y, desde ahí, "penetrar en los principios filosóficos que presiden á la manifestacion verbal del pensamiento". Esto es, se requiere de una formación amplia no circunscrita a los parámetros de la escuela, marcada por la presencia de la Academia, algo que también reclamarán otros autores a lo largo del último cuarto del siglo ${ }^{48}$.

La relación entre la lengua y el pensamiento en los planteamientos didácticos aparece de manera mucho más contundente en sendos artículos en la sección doctrinal traducidos del francés, ambos aparecidos en 1875. El primero de ellos es el segundo artículo de la serie "El papel de la memoria en las escuelas primarias" (EME, año IX, n. $\left.{ }^{\circ} 446,20-\mathrm{II}-1875\right)$, publicado originalmente en Le Progrés de Bruselas, donde se aborda el papel de la enseñanza de la lengua francesa en el desarrollo del entendimiento y en especial, de la memoria, si bien, como se indica en nota, se considera su contenido aplicable a la enseñanza de la lengua castellana. En este texto, al igual que ocurría en el de Alda, se otorga a las enseñanzas lingüísticas un papel central en las materias de enseñanza y, muy especialmente, haciéndose eco de las ideas de Condillac, en el desarrollo de las ideas, por lo que el estudio de la gramática se concibe como "un ejercicio de la inteligencia". Algo similar se plantea en el segundo artículo, "Cuáles deben ser los principios naturales de un buen método para la enseñanza de la lengua materna" escrito por L. Bard en L'Educateur (EME, año IX, n. 460, 30-IV1875), cuando se indica que "todas las dificultades que encontramos en la práctica de la lengua provienen en definitiva de la misma causa: esto es, que nosotros no comprendemos la relación que existe entre el pensamiento y la palabra".

47 En EME, por ejemplo, Gómez de Salazar responde a algunas dudas planteadas al respecto del análisis en el ya mencionado artículo "Cuestión gramatical”, en junio de 1876.

48 Esta aspiración de Alda encontrará su lugar algunos años después, con la ampliación de la formación lingüística que experimenta el plan de estudios de las Normales de 1889 (véase García Folgado 2017). 
La idea que está presente en estos artículos, así como en otros que abordan tangencialmente esta temática, es la de que el lenguaje es el vehículo de la inteligencia y el lazo de unión entre los seres humanos y se concibe la palabra

como expresión del interior del hombre, y la más apropiada, pues parece estar compuesta de un elemento espiritual y otro material, se le ha concedido al hombre para comunicar con sus semejantes, con aquellos que pudieran interpretar lo significado y significar á su vez lo comprendido. Y como entre los seres de este mundo visible los que gozan de este privilegio son los hombres, de ahí pues el vínculo de unión, entre ellos es el lenguaje (Mariano Pérez Olmedo, "Concepto de la segunda enseñanza", $E M E$, año IX, n. $\left.{ }^{\circ} 499,15-X I-1875\right)$.

De ahí que las propuestas didácticas se basen, precisamente, en el análisis de la relación entre la palabra y el pensamiento, esto es, en que los niños aprendan los mecanismos lingüísticos que construyen el significado, para lo cual es indudable el valor de la teoría gramatical. En este punto se observa una diferencia entre los dos artículos considerados: si el de Le Progrés se hace eco de las teorías inductivas a través de los postulados de Bréal, entre otros, -la teoría se subordina a la práctica y a la gramática, a las reglas, solo se llega tras un trabajo previo con la propia lengua ${ }^{49}$, para Bard es necesaria una aproximación deductiva, esto es, es necesario instruir al niño en ciertas nociones generales que le permitan aproximarse a los hechos del lenguaje: "Al que quiere estudiar la lengua, le hacen falta nociones ideológicas positivas, como necesita nociones de aritmética el que quiere aprender álgebra. Fuera de esto, todo conocimiento de la lengua no será más que rutinario é ilusorio". No obstante, ambos coinciden en la necesaria sencillez de las nociones gramaticales que han de estar ajustadas al nivel de conocimientos de los discípulos.

Además de estos artículos, también se recogen algunas notas sobre la enseñanza del castellano en las provincias bilingües, donde se evidencia el reconocimiento a la situación lingüística existente (algo que no siempre aparece al tratarse esta cuestión); así, al hilo del acuse de recepción de $E l$ auxiliar del maestro catalán de Genís se indica:

49 El texto, de hecho, incide en la importancia de que el método sea una prolongación de la instrucción de la madre, un aspecto capital para los seguidores del método intuitivo, como Bréal o como Thomas Braun, profesor de la Escuela Normal de Nivelles, al que se cita en el último artículo de la serie (año IX, n. ${ }^{\circ} 448,28-$ II-1875). 
si la enseñanza del castellano ofrece sus dificultades en las provincias en que este es idioma usual, mucho más en donde su uso está limitado á cierto círculo social. Así es que los Maestros de Cataluña tienen un doble trabajo para enseñar la lengua castellana, pues necesitan una gramática especial como si de un extranjero se tratara (EME, año VI, n. ${ }^{\circ}$ 256, 30-VI-1872).

No obstante, más allá de esto, se plantea la necesidad de que el castellano sea la única lengua del aula -"Como la práctica es el mejor sistema para la enseñanza de los idiomas, deben procurar [los maestros] que sus alumnos no hablen más que castellano dentro de las aulas" (EME, año XIV, n. ${ }^{\circ} 845$, 5-IX-1880)-, sin descartar las lenguas regionales, pero desplazándolas de la escuela. Esto último se aprecia claramente en la columna titulada "Lengua Eúskara" (EME, año XIII, n. ${ }^{\circ}$ 77, 25-VIII-1879), en la que se responde a un comentario hecho por la Asociación de Maestros de Huesca que se manifiesta en contra de premiar al maestro de escuela "que más haya hecho en pró de la lengua euskera", con el argumento de que no solo lo legal es enseñar únicamente castellano, sino también de que hacer lo contrario sirve a "causas que rechazan el interés de la patria y las aspiraciones del siglo que vivimos"; el redactor de $E M E$ no ve problemas en que los maestros se dediquen a la lengua vasca siempre que sea con "un carácter privado" y estén guiados "por un interés puramente filológico", ya que reconoce que se trata de una lengua "que si nos fuera dable conocer sus orígenes se resolverían muchos problemas que tan agitado tienen hoy al campo científico, por el interés que encierra el conocimiento de los tiempos prehistóricos".

Por último, se localizan algunas cuestiones muy puntuales como una apreciación sobre la enseñanza de la gramática castellana en Secundaria a partir del comentario sobre el plan de estudios del 13 de agosto de 1880 ( $E M E$, año XIV, n. $\left.{ }^{\circ} 848,20-I X-1880\right)$, donde se incide en la necesidad de que los catedráticos de la materia, que aunaba latín y castellano, presten atención al estudio del castellano también y no solo al del latín: "casos hay", dice el redactor, "de quien llega al grado de Doctor sin haber recibido más lecciones de Gramática castellana que las que en la escuela aprendió, por un Epitome que es bastante defectuoso y, sobre todo elemental". Queja similar había expresado, algunos años antes, Gómez de Salazar en el artículo "La base de la enseñanza" (EME, año IX, n. ${ }^{\circ} 649,15-X I I-1877$ y n. $\left.{ }^{\circ} 650,20-X I I-1877\right)$. 


\section{A MODO DE CIERRE}

Este necesariamente limitado recorrido por las páginas de El Magisterio Español nos ha permitido, por una parte, valorar el enorme potencial de la prensa pedagógica como insumo para reconstruir las ideas lingüísticas y lingüístico-pedagógicas de un periodo dado. Nos planteábamos antes de iniciar este trabajo que si, como hemos abogado en diferentes lugares, la historia de la gramática española, al menos hasta el siglo XX, es, en gran medida, la historia de un género didáctico - en tanto que la gramática es concebida, principalmente como objeto de enseñanza, y por, tanto, los textos, en sus diferentes formatos y diversos destinatarios, son, en puridad, obras concebidas para la enseñanza- y si a esto sumamos que se trata de una materia considerada central por los docentes y pedagogos - reiterada es la idea del valor de la lengua como puerta del conocimiento-, no era descabellado aventurar la presencia en la prensa profesional de textos que se ocuparan de ella de manera habitual. Ciertamente, como se ha podido apreciar, lo lingüístico ocupa un lugar destacado en $E M E$, con una gran diversidad de artículos que abordan tanto aspectos de orden interno como externo.

Por otro lado, hemos podido aproximarnos a las ideas lingüísticas de un autor concreto, Fernando Gómez de Salazar, que es sin duda alguna, el motor de lo lingüístico en la década analizada: sus opiniones impregnan el diario, especialmente entre 1871 y 1874 , los años, sin duda, con mayor presencia de los aspectos gramaticales en el periodo analizado, a la vista de la amplitud con que se tratan los temas y el alcance de las polémicas emprendidas. Se trata de un gramático periodista, o un periodista gramático, que encuentra en la prensa el lugar idóneo para dar difusión a sus ideas sobre la lengua. Estas se caracterizan, principalmente, por un acercamiento científico a los hechos lingüísticos, a través del análisis de los usos de la lengua, lo cual le lleva, en muchas ocasiones, a rechazar los postulados de otros gramáticos y, significativamente, la Academia, en una búsqueda de notoriedad para él y su obra. No se trata de un rechazo a la autoridad, per se, que admite, aunque no sin crítica, en el ámbito lexicográfico y ortográfico, sino la manifestación de una discrepancia que se pretende articular como debate científico, enfrentando la doctrina académica con la lengua usual. En sus propias palabras, que, creemos, resumen muy bien el talante de los artículos del autor: "La ciencia no se impone hoy por el Magister dixit, sino por la persuasion" (EME, año VIII, n. $\left.{ }^{\circ} 386,20-I V-1874\right)$. 


\section{REFERENCIAS BIBLIOGRÁFICAS}

Adelung, Friedrich von. 1815. Catherinens der Grosse Verdienste um die Vergleichende Sprachenkunde. Sankt Petersburg: Drechsler.

BALBI, AdRIAN. 1826. Atlas etnographique du globe, ou classification des peuples anciens et modernes d'après leur langue, précédé d'un discours sur l'utilité et l'importance de l'étude des langues appliquée à plusieurs branches des connaissances humaines. París: Rey et Gravier.

BuzeK, Ivo. 2014. Reseña bibliográfica de Enrique Jiménez Ríos. 2013. La crítica lexicográfica y el Diccionario de la Real Academia Española. Obras y autores contra el Diccionario. Anejos de Revista de Lexicografía 21. A Coruña: Universidade da Coruña, Revista argentina de historiografia lingüística 6/1: 89-94.

Catalina del Amo, Severo. 1861. La gramática de la lengua castellana tiene más de semítica que de latina: discursos leidos ante la Real Academia Española el día 25 de marzo de 1861 en la recepción pública. Madrid: Establecimiento tipográfico de Don Luis García.

CheCa Godoy, Antonio. 1993-94. Apuntes para un censo de la prensa pedagógica en España. Historia de la Educación XII-XIII: 595-610.

DuRÁN LóPEZ, FERNANDO. 2018. Estructuras de la prensa en el Cádiz de las Cortes: propuestas metodológicas. Cuadernos de Ilustración y Romanticismo 24: 419-436.

Eguibar Galarza, Mercedes. 1992. Orígenes y fundación de El Magisterio español. Periodo 1866-1869. Tesis doctoral para optar al grado de Doctora en Historia de la Educación. Universidad Nacional de Educación a Distancia (España).

EsTeBAn, LEÓN Y LóPEZ MARTín, RAMÓN. 1992. La prensa pedagógica en su devenir histórico (antecedentes de la Revista Española de Pedagogía). Revista Española de Pedagogía 192: 217-256.

EzPeleta Aguilar, Fermín. 2015. La prensa pedagógica del XIX como fuente para historiar la didáctica de la lengua. Ianua. Revista Philologica Romanica 15-16: 159-171.

García Folgado, María José. 2012. Gramática y legislación educativa. En Zamorano Aguilar, Alfonso (ed.), Reflexión lingüística y lengua en la España del XIX: marcos, panoramas y nuevas aportaciones, pp. 247-268. Münster: Lincom [Colección: Studies in Romance Linguistics, 70].

2017. La formación lingüística para el magisterio: las Contestaciones sumarias a los programas de gramática de Cervera y Royo (1898). Revista Argentina de Historiografía Lingüistica 9/2: 97-113.

2019. La enseñanza de la gramática como práctica reflexiva: aproximación histórica. Ponencia presentada pronunciada en el III Congreso Internacional sobre Enseñanza de la Gramática, Barcelona, España. Disponible en: https://youtu.be/mf0Hrg8xWDk

2020. Creencias y actitudes sobre la lengua de enseñanza en la España del siglo XIX. En M. Rivas Zancarrón y V. Gaviño Rodríguez (eds.). Creencias y actitudes ante la lengua en España y América (siglos XVIII y XIX), pp. 67-84. Madrid/Frankfurt: Iberoamericana/ Vervuert.

Gaviño Rodríguez, Victoriano. 2021. Gómez de Salazar y Jiménez, Fernando (¿?-1879). Biblioteca Virtual de la Filología Española (BVFE). Disponible en https://bvfe.es/es/ autor/23210-gomez-de-salazar-y-jimenez-fernando.html [consulta 10/01/2021].

(en prensa). La polémica lingüística como tipología discursiva en la prensa española del siglo XIX. Los discursos polémicos de Fernando Gómez de Salazar. Pragmalingüística 29.

(en prensa b). La oficialización de la ortografía española académica. Historia, propuestas y debates en la prensa española de la primera mitad del siglo XIX. Nueva Revista de Filología Hispánica. 
Gómez de Salazar, Fernando. 1870. Compendio de la gramática de la lengua castellana. Madrid: Imprenta de J.M. Lapuente.

JimÉNEZ Ríos, ENRIQUe. 2013. La crítica lexicográfica y el Diccionario de la Real Academia Española. Obras y autores contra el Diccionario. Anejos de Revista de Lexicografia 21. A Coruña: Universidade da Coruña.

Montoro del Arco, Esteban T. 2019. Métodos y modelos de representación del análisis sintáctico en la gramática escolar española (siglos XIX y XX). En A. Zamorano Aguilar (coord. y ed.). / A. González-Fernández, S. Rodríguez-Tapia y J. M. González Jiménez (eds.). Historiografia de la reflexión sintáctica: metaanálisis y estudios en torno al español, pp. 303-335. München: LINCOM.

Puche Lorenzo, Miguel Á. 2019. La utilidad de lo efímero en el estudio de la lengua del s. XIX: cuestiones gramaticales a través de la prensa. Anuari de Filologia 9: 179-202.

Real Academia Española. 1869. Diccionario de la lengua castellana. Undécima edición. Madrid: Imprenta de Don Manual Rivadeneyra.

1870. Gramática de la lengua castellana. Madrid: Imprenta y Estereotipia de M. Rivadeneyra.

Rivière Gómez, Aurora. 2000. Orientalismo y nacionalismo español. Estudios árabes y hebreos en la Universidad de Madrid (1843-1868). Madrid: Dykinson.

SASTRE, José L. 1966. El Magisterio Español. Un siglo de periodismo profesional. Madrid: Editorial Magisterio Español.

Vericat Núñez, Alfonso. 1992. El Magisterio Español, 1936-37-38: un modelo de prensa especializada durante la Guerra Civil. Tesis doctoral para optar al grado de Doctor en Ciencias de la Información. Universidad Complutense de Madrid. 